Aus der dermatologischen Universitätsklinik (Professor Jacobi) zu. Freiburg i. Br.

\title{
Zwei Fälle von ausgedehnten Ulzerationsprozessen an Mund und Genitalien, hervorgerufen durch Diphtheriebazillen. (Subalkute Haut- und Schleimhaut-Diphtherie.)
}

Von

\author{
Dr. Th. Schwab,
}

früherem I. Assistenten der Universitätshautklinik in Freiburg i. Br.

Im Verlaufe der letzten Jahre hatten wir Gelegenheit, zwei interessante Fälle von Ulzerationsprozessen an der Vulva bei gleichzeitigen Geschwüren der Mundhöhle zu beobachten.

Wegen der Eigenart des klinischen Verlaufes und bakteriologischen Befundes sei es gestattet, die Fälle des genaueren mitzuteilen.

F a 11 I. Anamnese: B. S. Kind einer P. p. war bis zum 10. Lebensjahre bei Pflegeeltern, seither in einer Erziehungsanstalt. Soweit sich feststellen ließ, war Pat, abgesehen von Masern im 7. und Typhus im 13. Lebensjahre, immer gesund. Seit 3 Tagen bestehen Schmerzen beim Gehen und Wasserlassen. Ein Arzt stellte Lues fest und veranlaßte die Überführung der Pat. in die Univ.-Hautklinik. Zu erwähnen wäre noch, daß in den letzten Monaten weder Diphtherie, noch irgend eine Halsentzündung unter den zahlreichen Kindern der betreffenden Anstalt aufgetreten ist.

Status: Am 6./IV. 1901. Bei dem anämischen 16jähr. Mädchen, das in der Fntwicklung stark zurückgeblieben ist, fällt neben einer mäßigen Gedunsenheit des Gesichtes fleckige Rötung mit einem Stich ins Blaue an beiden Wangen und Stinne auf. Ebensolche Flecken sind an den Armen vorhanden, die an den Streckseiten deutliche Keratosis pilaris aufweisen. Auf dem Rücken findet sich vom Nacken bis zum Kreuzbein herab in der Mittellinie feiner Haarwuchs. Im Munde bemerken wir an verschiedenen Stellen der Wangenschleimhaut und des 
Zahnfleisches scharf umschriebene Substanzverluste. Am Rande derselben findet sich kaum eine Veränderung gegen die gesunden Partien, abgesehen von einem schmalen, frischroten Saume. Ein nennenswertes Infiltrat fehlt. Mit dem festhaftenden gelblich-weißen Belag erreicht das Geschwür gerade das Niveau der übrigen Schleimhautoberfläche. Bei stärkerem Kratzen läßt sich die Auflagerung wie eine Membran abziehen, dabei tritt geringe Blutung und minimaler Schmerz ein. Spontan machen die Ulzerationen keine Beschwerden, so daB Pat. erst durch uns von deren Anwesenheit erfuhr. Ihrem Sitze nach bevorzugen die Substanzverluste absolut nicht etwa Stellen, die einer mechanischen Läsion ausgesetzt sind, (Zahnfleischrand gegen die Zähne, Wange, da wo die Zähne anliegen). Die Kranke hat eine mäßige Rhinitis, ${ }^{1}$ ) die, wie sie angibt, so lange wie die Genital-Affektion besteht.

An den Labia minora und am Präputium clitoritis finden wir starkes Ödem. Gleichzeitig sind diese Teile blaurot gefärbt, zeigen aber keine Haut-Läsion. Bei Auseinanderziehen der Labien bekommt man ein flaches Geschwür zu Gesicht, das neben mäßiger Menge dünnen Eiters einen festhaftenden, gelblichweißen Belag und einzelne nekrotische Fetzen aufweist. Dieses Geschwür, das in der Mitte nur wenig vertieft ist, umfaßt die mittlere Partie der Innenfläche der kleinen Labien und geht direkt bis zum mäßig infiltrierten Rande derselben. Hier finden sich einige, etwa stecknadelkopfgroße Pustelchen; die Scheide ist, soweit man sehen kann - ein stärkeres Auseinanderziehen der Labien ist zu schmerzhaft - normal; das Hymen intakt.

Die inneren Organe sind ohne Abnormitäten, der Urin ist frei von Eiweiß und Zucker, der Appetit ist exhalten, das Allgemeinbefinden "zeigt keine Störung. Bei rubigem Liegen und auch bei ganz vorsichtigem Gehen ist Pat. schmerzfrei.

Da das vorliegende Krankheitsbild auf keine der an diesen Stellen häufiger vorkommenden Erkrankungen zu beziehen war, und im Geschwürssekret verdächtige Stäbchen zu sehen sind, hatte Prof. Jacobi sofort Verdacht auf Diphtherie, es wurden sogleich Kulturen angelegt, die aber nur Staphylo- und Streptokokken ergeben.

11./IV. Nach Anlage neuer Kulturen gelingt es heute endich im hygienischen Institut, neben zahlreichen Staphylo- und vereinzeltenstreptokokken, reichlich typische Diphtheriebazillen zu finden. Darauf erhält Pat. abends eine Injektion von Behrings Serum Nr. 3. Der Status an diesem Tage ist kurz folgender: Abgesehen von einer Bronchitis leichten Grades, läßt sich an den inneren Organen nichts finden. Im Munde hat der Geschwürsprozeß entschieden zugenommen. Wir haben runde und eckige Ulzerationen, die aber tuberall noch denselben Charakter als flache Substanzverluste mit festhaftendem Belage tragen. Auch an der Lippe und der Zunge sind ähnliche Ulzera entstanden. Das Erythem an den Armen und

1) Leider wurde versäumt, Kulturen vom Nasensekret anzulegen. 
im Gesicht besteht in gleicher Weise weiter. An den Genitalien sind seit einigen Tagen Pustelchen aufgetreten, die teilweise konfluiert sind und dadurch die Ulzerationsfläche vergrößert haben. Die Geschwürsfläche zeigt immer noch denselben Charakter wie anfangs, nur reicht sie jetzt vorn bis zur Clitoris und hinten bis zur hinteren Kommissur. Es besteht ständig eine geringe Sekretion, leicht sanguinolenter Flüssigkeit.

13./IV. Während sich gestern keine Besserung gezeigt hat - die Temperatur ist nachmittags sogar auf 40 gestiegen - so ist heute entschieden eine solche zu erkennen. Die Zungengeschwüre sind in Abheilung, an den Labien ist die Schwellung geschwunden und die Sekretion bedeutend vermindert. $\mathrm{Da}$ abends das Fieber wieder ansteigt, wird nochmals Serum Nr. 3 injiziert.

15./IV. Nachdem die Temperatur am 14./IV. abends bis auf $37 \cdot 7^{\circ}$ gesunken, steigt sie heute auf $38^{\circ} 9^{\circ}$ an. Gleichzeitig erscheinen auf den gestern gänzlich gereinigten Ulzerationen wieder Beläge, ja sogar nekrotische Stellen. Die Sekretion ist stärker, die Genital-Ulzerationen sind schmerzhaft. Neue Pustelchen sind an der Außenfläche der Labien ent. standen, zum Teil in Gruppen geordnet, so daß bei der Anwesenheit eines Herpes febrilis der Uvula es sich auch hier sehr wohl um einen Herpes handeìn dürfte.

Der weitere Verlauf des Prozesses gestaltet sich nun folgendermaßen: Während einiger Tage bleibt der Status derselbe, die Temperatur überschreitet abends immer $39^{\circ}$ und zeigt einen remittierenden Typus. Am 23./IV beginnt die Reinigung der Geschwüre, der sich eine Ausheilung derselben ohne weitere Störung anschljeBt. Nur an der Zunge zeigen sich am 27./IV. nochmals neue Ulzerationen, die aber sehr rasch wieder verschwinden. Am 8./V. ist an den Genitalien nurmehr eine Rötung zu sehen, während in Munde vollständige Restitutio ad integrum eingetreten ist. Das Erythem ist ebenfalls verschwunden. Die Temperatur zeigt am 2./V. einen entschiedenen Rückgang unter $38^{\circ}$, wird jedoch erst vom $16 / V$. ab normal. Am 10./VI. wird Pat. entlassen, nachdem sie fast einen Monat frei von irgend welchen Erscheinungen gewesen ist. Nur noch eine mäBige Anämie erinnert an die überstandene Krankheit und eine weiche, von der umgebenden Haut sich höchstens durch einen leicht rötlichen Farbenton abhebende Narbe am labium majus.

Therapentisch haben wir, abgesehen von den schon erwähnten Seruminjektionen, Kali chloricum zum Gurgeln gegeben und an den Genitalien Umschläge mit Borsäurelösung machen lassen, da Pat. die an den ersten Tagen angewandte essigsaure Tonerde nicht ertrug. Zwischen die Labien kamen gleichzeitig mit Argentumlösung 1 : 3000 getränkte Kompressen. Daneben erhielt Pat. täglich ein Sitzbad von dünner Lösung von Kali hypermanganicum. Intern wurde die ersten Tage bis zum Diphtheriebazillen-Nachweis Jodkali $1 g$ pro die gegeben. Später wurde von jeder weiteren inneren Medikation Abstand genommen. Die zwei Injektionen von Behring-Serum Nr. 3 haben keinen entschiedenen 
Erfolg zu verzeichnen gehabt. Da siejedoch erst am 8 . Krankheitstage gemacht wurden, können sie unsere Diagnose Diphtherienichtin Fragestellen, weilderbakteriologische Befund zweifellos typische Diphtheriebazillen ergeben hat. Doch darauf wollen wir am Schlusse noch zurückkommen. Pat. wurde nach ihrer Entlassung aufs Land geschickt, kehrte dann wieder nach Monatsfrist in die Stadt zurück, wo sie sich ganz wohl befand, bis Anfang März folgenden Jahres. Zu einer Nachuntersuchung bestellt, ergab sich, daß wiederum an den Genitalien Ulzera aufgetreten waren, von denen sich nach Angabe des hygienischen Institutes diphtherieähnliche Bazillen kultivieren ließen. Pat. konnte erst, als Mitte April Schmerzen auftraten, bewogen werden, sich in die Klinik aufnehmen $\mathrm{zu}$ lassen.

Status: Das in seiner Ernährung immer noch etwas zurückgebliebene Mädchen zeigt sehr blasse Schleimhäute. Augen, Ohren, Nase o. B. Am Zahnfleisch des Oberkiefers findet sich oberhalb der mittleren Schneidezähne an der Übergangsstelle zur Lippenschleimhaut eine hanfkorngroße Erosion mit weißlichem Belag, innerhalb eines wenig geröteten Bezirkes. Dieselben Veränderungen, nur an einzelnen Stellen ohne Membranen, sehen wir am Oberkieferzahnfleisch rechts, an der Wangenschleimhaut des Kieferwinkels, auf der Oberlippenschleimhaut nahe dem Mundwinkel, am Zahnfleisch des Unterkiefers unterhalb des linken Eckzahnes und an der Wangenschleimhaut gegenüber dem untern ersten Prämolaren. Auch diesesmal handelte es sich wesentlich um Lokalisation an Stellen, die nicht etwa mechanischen Irritationen ausgesetzt sind.

Es findet sich eine ganz geringe rechtseitige Struma. Bei der Inspektion zeigt der Thorax, abgesehen von einer leichten Abflachung der Infra- und Supraklavikulargruben, nichts Abnormes. Lungengrenzen normal tief, gut verschieblich. Perkussionsschall sonor, an der rechten Spitze hinten leicht tympanitischer Beiklang. Linke Spitze hinten ausgesprochene Dämpfung. Atemgeräusch überall vesikulär. R. n. l., b. u. v. o. kleinblasige feuchte Rasselgeräusche, links zahlreicher als rechts. Am Herzen findet sich, abgesehen von einer geringen Verstärkung des 2. Pulmonaltones, nichts Abnormes. Auf der Hant ist keinerlei Exanthem zu sehen. Abgesehen von einzelnen kirschgroßen Inguinallymphdrüsen besteht keinerlei Drüsenschwellung.

Genitalbefund: Rechts: Labium minus bedeutend reduziert, an der Innenseite dieses Rudiments sieht man im vorderen Teile ein unregelmäßig begrenztes, quer ovales, überlinsengroßes, scharfrandiges, 2-3 mm tiefes Geschwür mit oberflächlichem gelbem Belag. Ein zirka erbsengroßes Ulcus von demselben Charakter befindet sich auf dem narbig: veränderten Labium majus nahe der hinteren Kommissur.

Links: Labium majus gerötet und geschwollen. Medial im vorderen Drittel ein fast pfenniggroßes, mäfig tiefes Geschwür, dessen Umgebung wallartig ansteigt. $1 \mathrm{~cm}$ davon entfernt beginnt eine fast bis zur hinteren 
Kommissur reichende länglich ovale, grobe Ulzeration, auf der sich teils gelbliches Sekret, teils deutlich nekrotischer Belag und nach dem äußeren Rande zu Borken und Krusten befinden. Das Labium minus ist nur in der vorderen Hälfte erhalten, am hinteren Ende desselben dehnt sich ein über pfennigstückgroßes, unregelmäßig begrenztes, scharfrandiges, an einzelnen Stellen bis $4 \mathrm{~mm}$ tiefes, mit gelblichem Belage bedecktes Geschwür aus, dessen Ränder nach innen dem Vestibulum zu sich deutlich wallartig emportürmen. An der hinteren Kommissur selbst ist ein kleines Geschwür. Im Vestibulum ist ziemlich viel gelbliches, dünnflüssiges Sekret, von den Ulzera herrührend. Das Hymen zeigt rechts oben einen älteren Defekt, ${ }^{1}$ ) Harnröhrenöffnung 0 . B. Da bei der ersten Untersuchung vor Monatsfrist diphtherieähnliche Bazillen gefunden wurden, bekommt Pat., obgleich der Nachweis von solchen nicht wieder gelungen - es sind nur Streptokokken und Pseudodiphtheriebazillen gewachsen - eine Seruminjektion Nr. 3. Da kein deutlicher Erfolg, zweite Seruminjektion Nr. 3 am 21./IV.

23./IV. Eine unzweidentige Besserung ist auf Serum nicht eingetreten; zwar haben sich die Ulzera an den Genitalien gereinigt, vielleicht sogar am Labium majus sinistrum etwas verkleinert, aber die Temperatur zeigt keine Änderung und am Zahnfleich des Oberkiefers namentlich rechts erscheinen neue Geschwüre; die übrigen in der Mundhöhle sind größer geworden. Am Tage nach der zweiten Seruminjektion ist eine Urtikaria aufgetreten, die über den ganzen Körper zerstrent, heftiges Jucken hervorrief und 5 Tage dauerte.

In den nächsten Wochen überhäuten sich, allerdings sehr langsam, die Genitalgeschwüre, bis auf einzelne Stellen, die keinerlei Heilungstendenz zeigen. Im Munde erscheinen zahlreiche Schübe von Ulzerationen, die alle genau den bisher beschriebenen entsprechen. Gleichzeitig sehen wir neben recht hohen Nachmittagstemperaturen starke Remissionen bald schon in später Abendstunde, bald erst am frühen Morgen folgen. $39^{\circ} 4^{0}$ und wenige Stunden später $37^{\circ}$ wird öfter gemessen. Merkwürdig gut ist während dieser ganzen Zeit das Allgemeinbefinden. Das Blut weist eine leichte Leukocytose auf, Blutkulturen bleiben immer steril. Vom 31./V. an treten nur vereinzelt Mundulzera auf, und gleichzeitig sinkt die Temperatur unter $38^{\circ}$.

In den ersten Tagen des Juni ist eine geringe Versohlimmerung an den Genitalien zu verzeichnen, wie uns der Status vom 6./VI. zeigt.

6./VI. Beiderseits einzelne bis bohnengroße, deutlich abgrenzbare Inguinal- und Schenkeldrüsen. An der hinteren Kommissur ist im Gebiete der weißen strahligen Narbe (einer Stelle, die erst seit wenigen Tagen überhäutet ist) links eine nicht ganz erbsengroße, ziemlich tiefe, gereinigte Ulzeration. Rechts findet sich über diese Narbe nach hinten hinausgreifend, ein etwa pfenniggroßes Geschwür, das aus einzelnen kle inen, mit gelblich-schmutzigem Belage versehenen Ulzera konfluiert ist.

1) Von Geschwüren bei ihrem ersten Aufenthalte herrührend. 
Nach vorn zu schließen sich Geschwüre an von derselben Größe, zum Teil ohne Belag, bis zum Rudiment des rechten Labium minus, das an seiner inneren Fläche wiederum ein Ulcus trägt. Links ist das Labium minus und Umgebung völlig überbäutet; auf und neben dem narbig veränderten Labium majus zeigt sich eine $4-5 \mathrm{~cm}$ lange und $1-1 \frac{1}{2} \mathrm{~cm}$ breite, anscheinend aus kleinen Ulzerationen konfluierte Fläche mit etwas erhabenen Rändern und weißgelblichen Belag.

An der Uvula finden sich ganz kleine Erosionen. Hier, wie an den vorderen Gaumenbögen besteht leichte Rötung. An der Zunge sind die Erosionen abgeheilt, eine geringe Einkerbung zurücklassend. Die Zunge zeigt mäßigen Belag. Die Schleimhaut der rechten Wange ist wieder normal. Links finden sich kleinste Erosionen an der Umschlagsfalte zum Zahnfleisch. Im Oberkiefer sind in ganzer Ausdehnung von Eckzahn zu Eckzahn zahllose, aber kaum stecknadelkopfgroße, oberflächliche Substanzverluste ohne Membranbildung. Ebensolche sieht man an der Schleimhaut der Oberlippe, wo einzelne Hanfkorngröße erreichen. Die gleichen Ulzera zeigt in geringer Anzahl das Zahnfleisch des Unterkiefers rechts und die gegenüberliegende Wangenschleimhaut.

Im Munde erscheinen weiterhin nur vereinzelte Ulzera. An den Genitalien tritt, nach vorübergehender Besserung nochmals für wenige Tage eine Progredienz der Geschwüre ein, macht aber bald einer definitiven Heilung Platz. Die Temperatur, die, wie erwähnt, bis zum 29./V. einen remittierenden Typas zeigte (Abendtemperaturen über $39^{\circ}$, Morgentemperaturen von $37^{\circ}$ ), ist bis zum 28./VI. nur noch wenig erhöht ( $\mathrm{MIa}$. ximum $38^{\circ}$ ), von da ab normal.

Beim Verlassen des Hospitals wird folgender Befund aufgenommen :

29./VIII. Pat. sieht gesund und kräftig aus, hat an Gewicht ganz erheblich zugenommen, $9^{1} / 2 \mathrm{~kg}$ und erfreut sich besten Allgemeinbefindens. Im Munde ist am Zahnfleisch, wie Wangen- und Rachenschleimhaut völlige Restitutio ad integrum eingetreten. Die Genitalien zeigen an stelle der Geschwüre weiche Narben, die sich kaum in der Farbe von der Ungebung abheben. Eine derartige Narbe umfaßt das ganze Labium majus rechts. Das Labium minus dieser Seite ist auf einen kleinen vorderen Teil reduziert. Links ist es nur in seinem hinteren Drittel in Verlust geraten; das Hymen ist teilweise zerstört. Die Einführung eines dünnen Fergussin spekulums ergibt, daß die Schleimhaut der Vagina und portio durchaus normal ist.

Was die Therapie bei dem 2. Aufenthalte der Pat, betrifft, so hat sie innerlich nichts erhalten. Subkutan wurden zwei Injektionen von Behring-Serum Nr. 3 gemacht. Lokal wurden Sitzbäder von verdünnter essigsaurer Tonerde gegeben; in den Pausen zwischen den einzelnen Bädern wurden die Genitalien mit Jodoformpulver eingepudert, darüber kamen Umschläge mit essigsaurer Tonerde. Die Mundulzera suchte man anfangs durch Pinselung mit Jodoform-Alkohol-Äther zu beeinflußen, erkannte aber bald die Nutzlosigkeit dieser Therapie und ließ nur häufig Ausspülungen mit verdünnter essigsaurer Tonerde machen. 
1./VIII. 1903. Nach eingezogenen Erkundigungen erfreut sich Pat. bis jetzt des besten Wohlbefindens.

Fall 2. Anamnese. B. M., 16 J. alt. Abgesehen von Rhachitis in ihrem 1. Lebensjahre, will Pat. bis zu ihrer jetzigen Krankheit gesund gewesen sein. Im Oktober 1900 traten zuerst Ulzerationen im Munde auf, die bis zu ihrer Aufnahme ins Hospital nie ganz verschwanden und nach ihrer Angabe genau so aussahen, wie die von uns beobachteten. Zeitweise waren Halsschmerzen vorhanden, Schnupfen fehlte immer. Pat. arbeitete noch bis Weibnachten 1900 als Kindermädchen auf dem Schwarzwalde, mußte sich aber in den letzten Tagen des Dezember wegen Müdigkeit und Abgeschlagenheit zu Bette legen. Anfang Januar bemerkte Pat. zuerst ein Geschwür an den Genitalien. Es vergrößerte sich eine Zeitlang, wurde dann kleiner, breitete sich dann wieder aus, und als es Markstückgröße erreicht hatte, wurde ein Arzt geholt. Es war dies Ende Februar 1901. Dieser verordnete Umschläge, Ausspülungen und Sitzbäder, ätzte auch öfters mit Lapis und ließ schließlich, als sich keine Tendenz zur Heilung zeigte, eine Schmierkur mit grauer Salbe machen. Da nach 5-6 Wochen noch kein Erfolg zu sehen war, schickte er Pat. ins hiesige Hospital, gleichzeitig teilte er uns aufier seinen oben erwähnten therapentischen Maßregeln mit, daß ein Exanthem nie aufgetreten sei. Den Angaben der Pat. wäre noch zu entnehmen, daß die ihr anvertrauten Kinder die ganze Zeit gesund waren. Diphtherie, oder auch nur Halsentzündungen, fehlten bei ihren Pflegbefohlenen ebenso wie zu Hause, wo weder ihre Eltern, noch ihre beiden Brüder von 8 und 12 Jahren in der Zeit vor oder während ihres Leidens erkrankten. Abgesehen von einer gewissen Müdigkeit und Abgeschlagenheit, die sie nur außerhalb des Bettes empfindet, hat sie keinerlei Beschwerden, Appetit und Schlaf ist immer gut gewesen.

Status vom 10./VII. Die blasse Pat. läBt auf der Haut keinerlei Exanthem erkennen. Die Lymphdrüsen sind nicht wesentlich geschwellt, mit Ausnahme zweier der linken Inguinalgegend. Die Mundschleimhaut zeigt, abgesehen von 2 Stellen der linken Tonsille, die eine entfernte Ähnlichkeit mit Plaques opalin. aufweisen, nichts, was auf Lues hindeutete. An den Genitalien findet sich links, in der Mitte des großen Labiums übergreifend auf das Labium minus eine etwa 3markstückgroße Geschwürstläche; die Ränder derselben sind erhaben und mäßig infiltriert, der Grund ist stark vertieft und mit Membranen von graugelber Farbe bedeckt, unter denen es bei Berührung sogleich blutet. Das Geschwür fühlt sich außerordentlich derb an, ist dabei gar nicht schmerzhaft, Hymen erhalten, Introitus ohne Besonderheiten. Lungen ohne Abnormität; am Herzen läßt sich ein leises systol. Geräusch an der Spitze feststellen (wohl anämisches Geräusch). Bauchorgane o. B. Urin frei von Eiweiß und Zucker.

17./VII. Die Plaques verdächtigen Stellen sind ohne jede Therapie verschwunden. An der Schleimhaut der Unterlippe ist rechts $1 / 2 \mathrm{~cm}$ vom Lippenrand und etwa $1 \mathrm{~cm}$ vom Mundwinkel ein etwa stecknadelkopfgroßes Geschwür entstanden. Es ist nur wenig gegen die Umgebung 
vertieft, so daß mit seinem festanhaftenden grauen Belag gerade das Niveau der Schleimhaut-Oberfläche erreicht wird. Der Rand ist kaum gerötet; die Ulzeration ist nur wenig schmerzhaft. Das Genitalgeschwür hat sich entschieden vergrößert, die Infiltration der Umgebung hat zugenommen.

20./VII. Das Geschwür an der Lippe hat sich sowohl nach der Fläche wie nach der Tiefe weiter ausgedehnt und zeigt deutlich infiltrierten Rand. Aus dem gestern von ihm zu Kulturzwecken entnommenen Belag ließen sich diphtherieverdächtige Bazillen im hygienischen Institut züchten. Auf der Zunge ist in der Nähe der Spitze eine leichte, wenig schmerzhafte Rötung entstanden. Wegen des Bazillenbefundes wird eine Einspritzung mit Serum Nr, 3 gemacht.

22./VII. Das Genitalgeschwür hat sich in allen Dimensionen vergrößert; wo Infiltration bestanden hatte, ist Zerfall eingetreten, so daß jetzt am Rande des Ulcus kaum Infiltration und nur geringe livide Färbung zu sehen ist. Der Geschwürsgrund ist ziemlich vertieft und immer noch mit festanhaftendem Belage versehen. Die Lippenulzeration ist gleich geblieben. An der Zungenspitze findet sich eine etwa stecknadelkopfgroße, scharf abgegrenzte Ulzeration in kaum geröteter und nur minimal infiltrierter Umgebung. Ihr graugelber, festhaftender Belag liegt im Niveau der übrigen Schleimbautoberfläche. Rechts findet sich an der Seite der Zunge, etwa am Ende des vorderen Drittels eine umschriebene Rötung. Injektion von Serum Nr. 2; die erste Einspritzung zeigte keinerlei Wirkung.

23./VII. Auch heute sieht man keinen Erfolg von der Injektion. Das Genitalgeschwür ist gut 5markstückgroß und zeigt am Raude immer noch leichte Infiltration. Es umfaßt die Innenfläche des ganzen großen Labiums links bis auf das vordere Drittel. Nach hinten reicht das Ulcus bis zur Kommissur; sein Belag läßt sich nur schwer abwischen, dabei empfindet die Pat. Schmerz und gleichzeitig blutet die Geschwürsfläche. Das Infiltrat des Geschwürsgrundes ist immer noch sehr stark, wenn es auch gegen Anfang des Spitalaufenthaltes zurückgegangen ist. Die Mundgeschwüre, 3 an der Zahl, schmerzen beim Essen in geringem Grade. Das bohnengroße Lippenulcus ist ziemlich vertieft mit entzündetem, wallartigem Rande versehen. Die Zungenulzerationen zeigen festbaftenden Belag. Ihr Rand ist kaum infiltriert. Das Allgemeinbefinden ist ungestört.

In den folgenden Tagen heilen die Mundulzera ab, von Zeit zu Zeit entstehen jedoch immer noch einzelne neue von demselben Charakter. Die Genitalgeschwüre breiten sich bis zum 9./VIII. weiter aus, dann tritt Stillstand und Reinigung der Ulzera ein.

Daß jedoch die Besserung noch keine dauerhafte ist, zeigt uns der Status vom 22./VIII., nach dem wiederum Beläge auf schon gereinigter Geschwürsfläche erschienen sind. In den nächsten Tagen vergrößern sich sogar die Inguinallymphdrüsen und werden schmerzhaft. 
Doch nach kurzer Zeit gehen alle Erscheinungen von seiten der Drüsen zurück und die Ulzera zeigen abermals einen Stillstand, nach ca. 14 Tagen jedoch beginnen sie von neuem wieder zu wachsen, wie aus dem Status vom 14./IX. hervorgeht.

14./IX. Seit gestern klagt Pat. über Schluckbeschwerden. Die Inspektion ergibt ein kirschkerngroßes, wie mit dem Locheisen geschlagenes, tiefes, eitrig belegtes Geschwür an der linken Tonsille. Letztere zeigt im übrigen gar keine pathologischen Veränderungen. Die Lymphdrüsen am Halse sind nicht wesentlich geschwollen. Die Ulzeration an den Genitalien ist auf der rechten Seite weiter gegangen, sodaß jetzt eine Geschwürsfäche besteht, die die hintere Hälfte beider großen Labien umfaßt, einschließlich der hinteren Kommissur. Überall findet sich gelblicher, festanhaftender Belag. Die Fläche ist besonders in ihrem hinteren Teile sehr schmerzhaft in der Ruhe wie bei Bewegung oder Berührung. Die Umgebung des Geschwüres ist wenig infiltriert und kaum druckempfindlich. Es wird wiederum Serum Nr. 3 injiziert.

15./IX. Objektiv ist nur an einer Stelle der Belag etwas weniger dicht. Dagegen hat Pat. heute nur geringe Schmerzen und hat auch die letzte Nacht besser geschlafen. Die Kultur von den Tonsillen ergab nur Streptokokken.

Noch einige 'Tage schreiten die Genitalgeschwüre weiter, dann tritt Stillstand ein. Die Ulzerationen reinigen sich, werden aber jetzt für kurze Zeit sehr schmerzhaft.

Allein bald entstehen, nicht nur im Munde, sondern auch an den Genitalien neue Geschwüre.

24./X. Pat. hat die letzte Nacht schlecht geschlafen, die Temperatur ist gestiegen, ebenso die Pulsfrequenz, die gestern abend 144, heute früh 120, heute abend 132 beträgt. Appetit gut. Während sich gestern am Herzen noch keine Veränderungen nachweisen ließen, besteht heute ein dentliches systolisches Geräusch an der Spitze bei verstärktem Pulmonalton. Die Herzdämpfung reicht oben bis zur zweiten Rippe, links in die Manmillarlinie, rechts zum rechten Sternalrand; der Spitzenstoß ist im 5. Intercostalraum deutlich sicht- und fühlbar in der Mammillarlinie. An den Lungen ist perkutorisch nichts nachweisbar. Bei der Auskultation hört man links hinten oben vereinzelte Rasselgeräusche, sonst keine Abnormitäten. Urin ohne Eiweiß und Zucker. Pat. klagt über geringes Magendrücken; der Stuhlgang ist in Ordnung. An der wenig geschwollenen, linken Tonsille zeigt sich im oberen Teil ein belegtes, ganz kleines Geschwür. ${ }^{1)}$ Es bestehen geringe Schluckbeschwerden; an der Haut finden sich rechts in der Mammillarlinie und etwas nach vorn und hinten übergreifend, teils vereinzelte, hellrote Papelchen, teils Pustelchen. Einzelne Papeln sind ringförmig angeordnet, ein Infiltrat

\footnotetext{
nachweisen.

1) Kulturell lassen sich hier nur Staphylo- und Streptokokken
} 
fehlt gänzlich, Jucken ebenso.') Die äußeren Genitalien sind ödematös, deutlich fühlt man die Lymphgefäße zu den Lymphdrüsen hinziehen, letztere sind ziemlich geschwellt, rechts weniger als links und wenig druckempfindlich. An der Innenfläche der kleinen Labien ist je ein über zehnpfennigstückgroßes, mit festanhaftendem, gelblich-weißem Belag versehenes, bei Berührung ziemlich schmerzhaftes Geschwür. Etwas nach hinten und innen davon finden sich kleinere Ulzera, die Reste der abheilenden früheren Geschwüre. Auf jeder Seite der Analoffnung ist ein, etwa kirschkerngroßes Gesehwïr.

25./X. Die Temperatur ist zurückgegangen, das Allgemeinbefinden besser. Am Herzen ist nichts Abnormes nachweisbar. Urin frei von Eiweiß und Zucker. Diazoreaktion negativ. Das Exanthem hat sich weiter gegen Brust und Rücken ausgebreitet, verursacht jedoch keine Beschwerden.

28./X. Pat. ist ganz fieberfrei. Der Ausschlag an Brust und Rücken hat sich nicht weiter ausgebreitet, hat sich auch nicht über die Papelbildung hinaus entwickelt. Die Effloreszenzen werden flacher, blassen ab und zeigen nur ganz geringe Schuppung. Der Juckreiz ist sehr gering, an den Extremitäten ist kein Exanthem aufgetreten. Die Genitalulzerationen sind frei von Belag und bluten leicht. Die beiden zirkumanalen Geschwüre sind jetzt etwa markstückgroß und konfluieren fast. Infiltration, wallartig erhöhte Ränder, fehlen gänzlich. Auf jeder Seite sind an der Innenfläche der Labia minora bzw. auf den Resten derselben, flache, wenig belegte Ulzera. Ihre nächste Umgebung ist ödematös; die gestern sebr heftigen Schmerzen an den Genitalien haben aufgehört. Die Lymphdrūsen der Inguinalgegend sind nur wenig geschwollen, links etwas schmerzhaft.

In kurzer Zeit schwindet das Exanthem völlig. Die Genitalgeschwüre heilen im Verlaufe des nächsten Monates ohne neve Exazerbation ab. Im Munde erscheinen fast bis zur Entlassung immer wieder vereinzelte typische Ulzera.

In ihrem Aussehen und ihrer Entwicklung entsprechen sie den bis dahin beschriebenen dieses Falles, wie auch den Mundgeschwüren von Fall I. Nur sei hervorgehoben, daß sie niemals in der Massenhaftigkeit aufgetreten sind, wie bei der ersten Pat. Dementsprechend ist die Temperatur im Falle II auch immer niedriger geblieben und hat $38^{\circ}$ nur einmal überschritten, als eine heftige Streptokokkenangina einsetzte, (am 23./X. und 24./X.)

Am 24./XII. wird Pat. aus dem Hospital entlassen, dabei wird folgender Befund festgestellt: Pat. sieht gut aus und hat an Gewicht in den letzten sechs Wochen über 6 Pfund zugenommen. Appetit und Schlaf ist ausgezeichnet. Schmerzen hat Pat. nur nnch ganz wenig beim Essen an

1) Dieses Exanthem rührt wohl samt den Allgemeinbeschwerden von Jodkali her, das die Pat. in den letzten Tagen erhalten hat. Das Mittel wird nunmehr ausgesetzt. 
der noch nicht abgeheilten Unterlippenulzeration. Lähmungen sind heute ebenso wenig, wie zu irgend einer Zeit ihres Hierseins zu konstatieren. Herz o. B., Lungen o. B. Urin frei von pathologischen Zusätzen. An den Genitalien findet sich nirgends mehr eine Ulzeration, obgleich seit dem 18/XII. jede Behandlung unterblieben war. Die Vulva klafft, da die Labia major. großenteils verschwunden sind und an ihrer Stelle bläulich-weiße Narben sich befinden. Von den kleinen Labien ist nur noch das vordere Drittel erhalten. Bis zum Anus das ganze Perineum entlang, sind dieselben Narben ; Pigmentation jeder Art fehlt. Die Lymphdrüsen zeigen keinerlei Schwellungen. Es wird nochmals abgeimpft und zwar von der Mundulzeration und dann von der Oberfläche der Narben an den Genitalien. Die Untersuchung ergab im Munde Staphylo- und Streptokokken, an den Genitalien die typischen, diphtherieähnlichen Stäbchen neben Kolibazillen. Nach 3 Wochen hat sich Pat. nochmals gezeigt; jetzt fehlte jede Ulzeration; die Geschwüre im Munde waren nach ihrer Angabe in etwa 3 Tagen geheilt und neue Ulzera sind bis jetzt nicht aufgetreten. Kulturen von Abstrichen der Genitalnarben, die übrigens seit der letzten Untersuchung sich nicht verändert haben; blieben steril.

Therapeutisch haben wir in diesem Falle ebensowenig wie im ersten besondere Erfolge zu verzeichnen. Die Seruminjektionen haben keinerlei augenfällige Besserung gebracht. Das Einreiben mit grauer Salbe war gänzlich wirkungslos. Jodkali konnte wegen Allgemeinstörungen nicht längere Zeit angewandt werden. Auch von der Lokaltherapie können wir uns nicht befriedigt erklären. Neben Sitzbädern mit Kalium hyperm., Arg. essigsaurer Tonerde, wurde in der Zwischenzeit angewandt: Einpudern mit Jodoform; Einpinseln mit Jodoform-Alk.-Äther oder Jodtinktur oder 96er Alkohol, oder Toluol-Alk. mit Ferr. sesqui chloratum. Ätzungen mit Acid. carbol. ließen auch im Stiche. Schließlich schienen JodoformEinpuderungen und Umschläge mit essigsaurer Tonerde noch am besten zu wirken. Auch die Mundulzerationen waren durch keine Therapie zu beeinflußen. Wir beschränkten uns zuletzt auf einfach desinfizierende Mundwässer.

Fassen wir nochmals kurz die beiden Krankheitsbilder zusammen, zuerst das zuletzt beschriebene. Bei Fall 2 besteht ein streng auf die Mundhöhle und äußere Genitalien beschränkter Geschwürsprozeß. Wir finden im Munde flache, mit fibrinösem gelblich-weißem, ohne Blutungen nicht entfernbaren Belag versehene Substanzverluste, die ohne Vorboten plötzlich auftreten und im allgemeinen keine stärkeren Bescbwerden verursachen. In der Regel scheinen sie von durchaus normaler Haut umgeben und weisen keinerlei Infiltrat auf. Sie vergrößern sich nur kurze Zeit in geringem Maße, um nach 
kürzerem oder längerem Stillstand bald ohne, bald unter ganz geringer Narbenbildung zu verschwinden. In ihrer Lokalisation bevorzugen sie durchaus nicht etwa Stellen, die mechanischen Insulten von Seiten der Zähne ausgesetzt sind und erscheinen gerade so gut an der Wangenschleimhaut, wie am Zahnfleisch. Während sie auch an der Zunge denselben Charakter aufweisen, besteht an der Lippenschleimhaut ein erheblicheres Infiltrat, wenn auch nicht in der Stärke, wie an den Genitalien. Hier finden wir ausnahmslos, so lange der Geschwürsprozeß progredient ist, starke Infiltration der Umgebung, vielfach sogar ein weit ausgedehntes, entzündliches Ödem. Die Ulzera sind meistens viel tiefer und mit einem dicken, fibrinös-eitrigen Belage versehen, der ohne Blutung und ohne Schmerzen nicht entfernbar ist. Die einzelnen Geschwüre haben im allgemeinen einen viel längeren Bestand, als in der Mundhöble, bleiben auch maist nicht auf das zuerst ergriffene Gebiet beschränkt, sondern dehnen sich längere oder kürzere Zeit weiter aus. Bei der Abheilung entstehen Narben, irgend welche Pigmentation fehlt jedoch gänzlich. In eigenartigem Gegensatze zu dem schweren und langdauernden Ulzerationsprozeß an den Genitalien steht die geringe Beteiligung des zugehörigen Lymphapparates. Nur während der Akme finden wir eine, jedoch sehr mäßige, wenig schmerzhafte Schwellung einzelner Lymphdrüsen und Lymphstränge. Sowie der Prozeß nur wenig sich bessert, verschwinden hier sofort alle Erscheinungen. Die übrigen, einer Palpation zugänglichen Körperlymphdrüsen lassen jede pathologische Veränderung vermissen. Der Krankheitsprozeß bleibt also streng auf das ergriffene Gebiet beschränkt. Dementsprechend wird das Allgemeinbefinden so gut wie gar nicht in Mitleidenschaft versetzt, eine erheblichere Temperatursteigerung unterbleibt. Denn das vorübergehende Fieber müssen wir wohl ebenso, wie die Störungen des Allgemeinbefindens das eine Mal auf eine zufällige Streptokokken-Angina, das andere Mal auf Jodkaliwirkung zurückführen.

Fall I zeigt hinsichtlich der Mundgeschwüre genau dasselbe Bild wie Fall II. Auch hier bleiben die Halslymphdrüsen vollkommen frei von allen Erscheinungen, und nach 
kürzerem oder längerem Bestande heilen die Ulzera ohne tiefere Narbenbildung. Während der ersten Attacke der Krankheit - unserer Ansicht nach haben wir es bei der 2. Aufnahme der Pat. mit einem Rezidiv des Leidens zu tun - ist der Prozeß ein akuterer, rascher ablaufender (Dauer ca. 2 Monate). Die Temperatur erreicht bedeutende Steigerungen, bis $40^{\circ}$. Allein auch hier leidet das Allgemeinbefinden kaum. An den Genitalien findet sich während der Progredienz ebenfalls Ödem der Umgebung, festhaftender Belag des Geschwüres, abweichend von Fall II und entsprechend der größeren Intensität des Krankheitsprozesses, teilweise $\mathrm{Ne}$ krosen. Welche Bedeutung das Erythem an Gesicht und Händen hatte, ließ sich nicht genau eruieren. Bei der Wiederaufnahme nach fast 10 Monaten treffen wir abermals die charakteristischen Mundulzerationen an, wiederum fehlt die Drüsenschwellung - von einer leichten, vorübergehenden Vergrößerung und Schmerzhaftigkeit der Inguinaldrüsen wird zwar berichtet fast gänzlich, trotzdem diesmal die Dauer und Intensität der Genitalveränderungen viel stärker sind, als beim ersten Aufenthalte. Auch die subjektiven Symptome treten in höherem Maße hervor, teilweise bestehen erhebliche Schmerzen an den Mund- wie Genitalgeschwüren. Aber das Allgemeinbefinden leidet trotz länger dauerndem und zeitweise recht hohem Fieber nicht wesentlich. Inwieweit der Proze $B$ an den Lungen - ob Tuberkulose oder nicht, ließ sich nicht sicher feststellen - die erhöhten Temperaturen mitbedingt hat, können wir nicht sicher entscheiden. Als Pat, nach 6 Monate langem Aufenthalte in der Klinik - die Dauer der Neuerkrankung datiert mindestens noch einen Monat weiter zurück - entlassen wird, ist Herz- und Lungenbefund ein normaler und die Ulzera sind ohne jede Pigmentierung, im Munde sogar ohne Bildung tieferer Narben abgeheilt. Trotz gewisser Abweichungen in beiden Krankheitsbildern möchten wir die Fälle doch als derselben Krankheit zugehörig ansehen.

Lassen wir den Bazillenbefund zunächst außer Betracht, so käme differentialdiagnostisch in erster Linie Lues oder Tuberkulose in Frage. 
Gegen Lues spricht so ziemlich alles im klinischen $\mathrm{Be}-$ fund. Wohl ist einmal im Fall I wie II von einer Plaque opalin. verdächtigen Stelle im Munde die Rede, die allerdings nur einen Tag besteht, allein die übrigen Geschwüre im Munde haben mit Plaques-opal., bezw. zerfallenden Schleimhautpapeln nicht die entfernteste Ähnlichkeit. Die flachen, mit fibrinösem Belag versehenen Ulzera, deren Umgebung kaum jemals irgendwelche Entzündungserscheinungen aufweist, können durchaus nicht als Effloreszenzen der Sekundärperiode imponieren. Für solche der tertiären waren sie durchgehends zu oberflächlich, bestanden zu kurze Zeit und heilten auch ohne tiefere Narbenbildung ab.

Die Genitalgeschwüre der Sekundärperiode zuzurechnen, geht auch nicht an. Es bestand keine einzige Effloreszenz. die nur entfernte Ähnlichkeit gehabt hätte mit einem Condyloma latum oder mit zerfallenden Papeln. Dazu kommt die Abheilung ohne jede Pigmentation, was uns auch unmöglich macht, die Genitalulzerationen dem tertiären Luesstadium zuzurechnen; und Stellen, die nur entfernt einem tubero-serpiginösen oder gummösen Syphilid ähnlich gewesen wären, hatten beide Fälle niemals aufzuweisen.

Gegen die Diagnose einer sekundären Lues wäre außerdem noch heranzuziehen das Fehlen der spez. Drüsenschwellung - es traten zwar an den Inguinaldrüsen leichte Schwellungen auf, aber diese waren weder typisch noch auch einigermaßen beständig - das Fehlen jeder Art eines makulösen oder papulösen, luetischen Exanthems an Rumpf oder Extremitäten, das bei der monatelang dauernden Beobachtung doch wohl nicht unbemerkt geblieben wäre. Wie wir sehen, spricht alles gegen Lues, das Aussehen der Einzeleffloreszenzen, der klinische Verlauf, insbesondere die Art der Abheilung.

Können wir die Fälle als Tuberkulose registrieren? Lungentuberkulose ist vielleicht, doch auch das ist unsicher, bei Fall I vorhanden. Als Lupus dürfen die Erscheinungen durchaus nicht aufgefaßt werden. Mit Haut- wie Schleimhautlupus hatten die Effloreszenzen absolut keine Ähnlichkeit und es fand sich niemals ein Gebilde, das als Lupusknötchen hätte 
gedeutet werden können. Wir müßten also an die ulzerösen, zu raschem Zerfall tendierenden Hauttuberkulosen denken. Gegen solche spricht einmal das andauernd gute Allgemeinbefinden der Pat., dann die Gestaltungen der Ulzera, das Fehlen miliarer Tuberkel an den Rändern der Geschwüre, die Art des Belages, der günstige Verlauf, die Abheilung der Geschwüre ohne jede eingreifende Behandlung. Nach dem soeben Gesagten müssen wir also auch die Diagnose Tuberkulose abweisen.

Von akuten Erkrankungen könnte man eventuell auch an $\mathrm{Maul-und} \mathrm{Klauenseuche} \mathrm{denken,} \mathrm{allein} \mathrm{dafür} \mathrm{verlaufen}$ unsere Fälle doch wieder zu milde. Die Allgemeinerscheinungen treten zu sehr zurück, die Mundulzera entbehren einer hochgradigen Schmerzhaftigkeit, die Extremitäten bleiben völlig rom Krankheitsprozesse verschont.

Für eine Sepsis ist der Fall ebenfalls zu gutartig, wenn gleich bei der Betrachtung der Temperatur bei Fall I eine gewisse Ähnlichkeit mit einer solchen bei Sepsis nicht in Abrede gestellt werden kann. Immerhin wäre das Bild ein äußerst merkwürdiges und ungewöhnliches, wenn man die geringe Störung des Allgemeinbefindens und die Stabilität der Lokalisation ins Auge faßt.

Dem Ulcus molle können wir wohl die Fälle nicht zurechnen. Einmal zeigt bei der Menge größerer und kleinerer Ulzera an den Genitalien kein einziges den Typus des Ulcus molle. Unerklärlich wäre auch, daß, nachdem schon gute Granulationen allenthalben vorhanden, plötzlich wiederum ein Rezidiv eintritt. Bei dem langdauernden Prozeß fehlt jede stärkere Drüsenbeteiligung, und endlich die Mundulzera als Ulzera mollia aufzufassen, scheint auch nicht wohl angängig. Schließlich müßte man bei so langer Dauer und so ausgedehnten Geschwüren ganz andere Zerstörungen erwarten.

$\mathrm{Pemphigus}$ bedarf kaum einer eingehenden Zurückweisung. Es sei nur betont, daß typische Pemphigusblasen niemals vorhanden waren, daß wir bei der vorwiegenden Beteiligung der Mundschleimhaut einen ganz bösartig verlaufenden Fall von Pemphigus hätten annehmen müssen; auch für Pem- 
phigus wäre dies Beschränktbleiben auf zwei ganz entfernte Stellen sehr merkwürdig.

So sehen wir denn, daß uns die Möglichkeit fehlt, die beiden Fälle in irgend ein bekanntes, event. ähnliche Symptome hervorbringendes Krankheitsbild einzureihen, und doch sind in beiden die klinischen Erscheinungen so typisch und prägnant und übereinstimmend, da $\beta$ wir beide als den Ausdruck derselben Krankheit ansprechen müssen.

Dazu stimmen nun auch in gewissem Sinne die bakteriologischen Befunde. Bei Fall I wurden während der I. Attacke sogleich Bazillen gefunden, die im hygienischenInstitut nach Wachstumund Färbung alsechteDiphtheriebazillenangesprochenwurden. Da keinerlei Zweifel obwalteten, wurde von der Impfung von Tieren abgesehen. Die vorgefundenen Bazillen beim zweiten Aufenthalt machten, abgesehen von der Säurebildung, die ganz der bei echten Diphtheriebazillen entsprach, und zeitweiser Neißerscher Körnchenfärbung nach ihrem morphologischen und kulturellen Verhalten den Eindruck von Pseudo-Diphtheriebazillen. Tierpathogenität fehlte.

Bei Fall II ließen sich auch diphtherieähnliche Stäbchen züchten, deren Verhalten ich an verschiedenen Kulturen durch die Liebenswürdigkeit des Direktors rom hygienischen Institut, Prof. Schottelius, in seinem Institut untersuchen konnte.

Nachdem wir durch Abspülungen mit Argentum 1:3000 die oberflächlichen Auflagerungen, die kulturell nur Staphylound Streptokokken ergaben, entfernt hatten, konnten wir Stäbchen in Reinkultur vorfinden, die auf den ersten Blick den Diphtheriebazillen ganz ähnlich sahen. Dieselben Gebilde trafen wir bis zur vollständigen Heilung der Ulzera, ja sogar noch auf den Narben. Gleichzeitig konnten wir uns auch überzeugen, daß die Mundgeschwüre die gleichen Bakterien beherbergten. Die Bazillen hatten folgende Eigenschaften:

Wir haben im hängenden Tropfen unbewegliche Stäbchen, die regelmäßig auf den ersten Blick als Diphtheriebazillen imponieren. Es fällt allerdings auf, daß die schlanken Formen gegen die kurzen dicken immer stark zurücktreten. Die Stäb- 
chen sind bald gleich dick, vielfach sind sie an einer Seite etwas angeschwollen, während sie an der anderen mehr spitz erscheinen. Einige Male dachten wir bei älteren Kulturen, es müsse eine Verunreinigung mit Kokken eingetreten sein, allein es zeigte sich, daß auch ganz kurze, kokkenähnliche, zum selben Stamme gehörten. Die Lagerung war bald die für Diphtheriebazillen, bald die für Pseudo-Diphtheriebazillen als typisch beschriebene. Mit den verschiedenen Anilinfarben tingieren sich die Bazillen sehr leicht und rasch. Nach der Grammschen Methode behandelt, halten sie das Gentiana-Violett durchaus fest. Die Neißersche Körnchenfärbung lionnten wir in den ersten 24 Stunden bei Serumkulturen nur einmal in der typischen Weise sehen. Trotz zahlreicher Versuche gelang diese Färbung nie wieder.

Kulturversuche: Auf Serum und Agar zeigt sich ein recht üppiges und gleich gutes Wachstum. Es bilden sich sehr rasch Leisten von zuerst weißlicher, später etwas bräunlicher Farbe. Die Kolonien unterschieden sich jedoch niemals darin von den gleichzeitig kultivierten echten Diphtheriebazillen. ${ }^{1}$ ) Auf Agar war das Wachstum bei unserem Stamme allerdings üppiger, als bei dem Kontrollstamme. Schon nach 8 Stunden ließ sich in den Klatschpräparaten von Serumkulturen eine sehr reichliche Vermehrung nachweisen. Dabei trat die für Diphtheriebazillen als typisch angesehene Lagerung sehr deutlich zu Tage. Auch die langen, schlanken Bazillen waren hier entschieden in größerer Anzahl vorhanden, wenn auch nicht so reichlich wie bei dem Kontrollstamme. Die Bouillon mit und ohne Zusatz von 2\% Traubenzucker wird in 24 Stunden mäßig getrübt und es findet sich ein bald mehr körniger, bald mehr schleimiger Bodensatz.

Im Grade der Trübung und der Art des Sedimentes ließ sich kein Unterschied gegenüber der Kontrollkultur feststellen, auch im weiteren Verlaufe verhielten sich beide Kulturen gleich. Nach ca. 3 Wochen war die Bouillon nahezu wieder klar.

1) Die Kultur, die zur Kontrolle Herr Dr. Erne vom hygienischen Institut freundlichst mir zur Verfügung gestellt hatte, entstammte einer sehr schweren Rachendiphtherie, die auf Serum prompt reagiert hatte. Meerschweinchen gegenüber zeigte sich die Kultur sehr virulent. Die Nei Bersche Körnchentärbung war immer typisch. 
Säuerung der Bouillon. Es wurde solche mit und ohne Traubenzuckerzusatz $(2 \%)$ verwendet. Die Titrierung geschah mit $1 / 40$ Normalnatronlange; als Indikator wurden 4-6 Tropfen einer alkoholischen Phenolphtaleinlösung zugefügt. Die Natronlauge wurde zugesetzt, bis die Flüssigkeit deutlich rosa erschien. Bei den Versuchen zeigte unsere Bouillon mit und ohne Zuckerzusatz eine Azidität, die $3.5 \mathrm{~cm}^{3}$ einer $1 / 40$ Normalnatronlange entsprach. Das Resultat der Untersuchungen zeigen folgende Tabellen: ${ }^{1}$ )

Bouillon ohne Zuckerzusatz:

$\begin{array}{ccc}\begin{array}{c}\text { Zunahme der Azidität } \\ \text { nach }\end{array} & \begin{array}{c}\text { Kultur isoliert von } \\ \text { der Vulva }\end{array} & \begin{array}{c}\text { Kontrollkultur aus dem } \\ \text { Hyg. Institut }\end{array} \\ 20 \text { Stunden } & 1.5 \mathrm{~cm}^{3} & 0.8 \mathrm{~cm}^{3} \\ 40 & 1.5 \mathrm{~cm}^{3} & 2.5 \mathrm{~cm}^{3}\end{array}$

Merkwürdig und unerklärlich ist hier das Verhalten der Vulvakultur. Allein in der Titrierung lag kein Fehler vor, wie wir uns durch zahlreiche Versuche überzeugten.

Anders steht es mit der Zuckerbouillon. ${ }^{2}$ )

$\begin{array}{ccc}\begin{array}{c}\text { Zunahme der Akzidität } \\ \text { in }\end{array} & \begin{array}{c}\text { Stamm isoliert von } \\ \text { der Vulva }\end{array} & \begin{array}{c}\text { Kontrollstamm aus dem } \\ \text { Hyg.-Institut }\end{array} \\ 20 \text { Stunden } & 1.9 \mathrm{~cm}^{3} & 1.1 \mathrm{~cm}^{3} \\ 40 & 4.25 \mathrm{~cm}^{3} & 3.5 \mathrm{~cm}^{3}\end{array}$

Der Tierversuch hatte sowohl bei Bouillon- wie AszitesKulturen immer negatives Ergebnis. Wir mochten 24 Stunden alte Kulturen verwenden, oder 48 Stunden warten. Sogar $3 \mathrm{~cm}^{3}$ einer 48stündigen Aszites-Kultur subkutan injiziert ließen auch bei jungen Meerschweinchen Krankheitserscheinungen nicht er-

1) Um das Übersehen einer etwa nachträglichen Säuerung der Untersuchungsbonillon zu vermeiden, wurden immer neben den infizierten Röhrchen auch sterile Bouillonröhrchen derselben Abkunft in den Brutschrank gestellt und jeweils mit titriert. Es ergab sich, daß während der Untersuchungszeit eine Veränderung des Säuregehaltes der Kontrollbouillon nicht eintrat.

2) Hier sei noch bemerkt, daf bei den Säureversuchen der Rest der betr. Bouillon auf die Reinheit der Kultur mikroskopisch und durch Verimpfung auf Agar festgestellt wurde. 
kennen. Die mit der Kontrollkultur geimpften Tiere starben immer sehr rasch.

Fragen wir nun: Gehört dieser uns vorliegende Stamm zu den Diphtheriebazillen oder nicht? Mit absoluter Sicherheit ist das nicht zu entscheiden. Wir möchten ihn jedoch für einen atoxischen, aber echten Diphtheriestamm betrachten.

In der reichhaltigen Literatur über Diphtherie- und Pseudodiphtheriebazillen finden wir ja keine absolut zuverlässige Abgrenzung der einzelnen Formen gegeneinander, vor allem dann, wenn es sich um Stämme ohne Tierpathogenität handelt. Werden doch alle die anderen morphologischen und biologischen Eigenschaften von den einzelnen Forschern verschieden beurteilt bezüglich ihres diagnostischen Wertes.

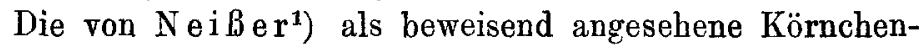
färbung wird einerseits bei einer, allerdings einige Monate alten, sicheren Diphtheriekultur von $\mathrm{He}$ in ersdorf $\mathbf{f}^{\mathrm{a}}$ ) noch nach 20 Stunden fast völlig vermißt, nicht angetroffen, andererseits will Reich en $\mathrm{b} \mathrm{ch}^{3}$ ) dieselbe erst nach einjähr. Züchtung auf künstlichen Nährböden bei einer sehr virulenten Kultur gefunden haben. Von allen kulturellen Merkmalen wird die Säuerung der Bouillon, wenn sie einigermaßen stark ist, noch am übereinstimmendsten anerkannt. ${ }^{4}$ ) Mit Recht betont deshalb Prochaska, ${ }^{5}$ ) daß eben nie ein einziges Merkmal als genügend für die Diagnose anzusehen sei, dali man immer mehrere heranziehen müßte.

Überblicken wir also nach dieser Richtung unsere Befunde, so spräche für Diphtherie: das rasche Wachstum der Kultur

1) Zur Differentialdiagnose der Diphtheriebazillen ron M. NeiBer, Zeitschr. f. Hygiene, 1897. Bd. XXIV.

2) Über das Vorkommen ... nebst einem Beitrage zur Frühdiagnose der Diphtherie von Hei uersdorf. Gräfes Arch. f. Ophthalmologie, 1898. Bd. XLVI.

3) Deutsche mediz. Wochenschrift 1899. Bd. XXV. p. 68. (Vereinsbeiage), Ref. über einen Vortrag, gehalten in der med. Gesellschaft in Göttingen am 12./I. 1899.

4) Vide, $\mathrm{N}$ eißer in seiner soeben zitierten Publik., dagegen auf der anderen Seite: D. Simoni, Beitrag z. Morph. u. Biolog. der Diphtheriebazillen, Zentralbl. f. Bakteriologie. 1899. Bd. XXVI.

5) Die Pseudodiphtheriebazillen des Rachens. Zeitschr. f. Hygiene. 1897. Bd. XXIV. 
schon nach 8 Stunden, die wenn auch nur einmal nachgewiesene Nei $\beta$ er sche Färbung, die Säuerung der Bouillon; das gleich gute Wachstum auf Serum und Agar läßt sich diagnostisch weder für noch gegen Diphtheriebazillen heranziehen.

Wir möchten die Bazillen als echte Diphtheriebazillen betrachten und glauben dazu um. somehrBerechtigung zu haben, als im Falle I, der, wie ersichtlich, klinisch denselbenCharakter aufwies, sicher Diphtheriebazillen nachgewiesen wurden.

Man könnte nun vielleicht einwenden, daß das ganze klinische Bild doch unsere Diagnose recht unwahrscheinlich macht. Das stimmt im gewissen Sinne für die bis dahin beschriebenen akuten Diphtheriefälle von Haut und Schleimhaut. Allein gerade in den letzten Jahren sind sebr eigentümliche Beobachtungen gemacht worden.

$\mathrm{Zu}$ erwähnen wäre in erster Linie die Publikation von Neißer und Kahnert. ${ }^{\mathbf{1}}$ ) Hier ist auch der Beweis, daß die aufgefundenen Bazillen echte Kl e b s - Lö ffl er sche DiphtherieBazillen sind, bei den meisten Fällen durch das positive Tierexperiment erbracht. Allein gerade unter diesen Kulturen fand sich auch ein atoxischer und avirulenter, aber zweifellos echter Diphtheriestamm. ${ }^{2}$ ) Hierher gehört auch der von $\mathrm{Jesse}^{3}$ ) publizierte Fall, wo sich auch Ulzerationen und Infiltrate finden. Doch bei beiden Autoren handelt es sich um Kranke mit Rachenaffektion.

Wie steht es mit Wunddiphtherien? Unter den Fällen mit Vulvadiphtherien haben wir keinen angetroffeu, bei dem eine Ähnlichkeit mit unserer vorliegenden Krankheit hätte gefunden werden können. Es handelt sich immer um akute und akuteste Fälle, die meist in Verbindung mit einer floriden Rachendiphtherie in Erscheinung traten und auf Serum meist Bd. XXVI.

1) Neißer und Kahnert deutsch. mediz. Wochenschrift Nr. 33.

2) Die Untersuchungen über diesen Stamm sind von Lubowski publiziert worden. Zeitschr. f. Hygiene 1900. Bd. XXXV. p. 87.

3) Über prolongierte Diphtherie. Zentralbl. f. innere Medizin 1897. Bd. XVIII. Nr. 19. p. 449. 
prompt reagierten. ${ }^{1}$ ) Bedeutend näher kommt unserem Falle ein solcher von Brunner. ${ }^{9}$ ) Wir haben hier ein drei Wochen bestehendes schmutzig-grauweiß belegtes Ulcus am Ringfinger, das typische Diphtheriebazillen enthielt. Endlich sei noch eine zweite Beobachtung Brunners ${ }^{3}$ ) erwähnt; es handelte sich um einen Mann, der nach einer phlegmonösen Entzündung am Skrotum noch zwei Rezidive an derselben Stelle bekam, bei derem letztem die bakteriologische Untersuchung typische Diphtheriebazillen ergab; auch hier fehlte jede Art von Allgemeinerscheinungen.

Fügen wir weiter noch zu, daßauch in $\mathrm{Panaritie} \mathbf{n}^{4}$ ) in Eiterpusteln, ${ }^{5}$ ) die sich in der Nähe von Ulzerationen befanden und die in dem betreffenden Falle als der Ausgangspunlat des Ulcus angesehen wurden, echte Diphtheriebazillen als Krankheitserreger nachwejsen ließen, so fällt für uns jedes Bedenken weg, das man in klinischer Beziehung an der Diagnose Diphtherie hätte haben können.

Wir möchten unsere beiden Fälle als subakute Diphtherie mit Rezidiven bezeichnen, die Fälle also gleichsam als Mittelglieder zwischen den akuten und chronischen Diphtherien betrachten. Das gute Allgemeinbefinden der Pat. kann in deren Alter einerseits, und in der mangelnden Toxizität der Bazillen andererseits begründet sein. Das Fehlen der Serumwirkung läßt sich sehr wohl durch die späte Anwendung des Mittels erklären. Wo sich die Krankheitserreger zuerst lokalisiert haben, im Munde oder an den Genitalien, ließ sich nicht eruieren. Jedenfalls dürfte eine Verschleppung auf dem Blutwege als ausgeschlossen zu betrachten sein. Wahrscheinlich

1) Die Literatur betreffend, möchte ich nur die Arbeit von Leich (Deutsche med. Wochenschr. 1900. Nr. 12) erwähnen, wo auf eine Reihe anderer Fälle hingewiesen ist.

$\left.{ }^{2}\right)$ Eine weitere Beobachtung von Munddiphtherie. Berliner klin. Wochenschr. 1894. Bd. XXXI. Nr. 13. p. 310.

3) Über Wunddiphterie. Berliner klinische Wochenschr. 1893. Band XXX. p. 547.

4) Seitz Korrespondenzblatt Schweizer Ärzte 1899.

5) Müller, Über seltene Lokalisation der Diphtheriebazillen auf Haut und Schleimhaut. Deutsche mediz. Wochenschrift 1899. Bd. XXV. Nr. 6. p. 91. 
sind die Keime durch die Hände von einer Stelle zur andern übertragen worden. Erwähnen wollen wir noch, daß sich die Fälle auch insofern als sehr gutartig darstellten, daß keine Infektion der Umgebung eintrat, obgleich die eine Pat. noch während ihrer Erkrankung Kindermädchen war und die andere sich in einem Pensionat befand, das noch zahlreiche Kinder beherbergte, eine bei der geringen Virulenz der Bazillenstämme nicht unerklärliche Erscheinung.

Zum Schlusse habe ich die angenehme Pflicht, meinem verehrten Chef Hrn. Professor J a c o bi für die Überlassung dieser Fälle, sowie Herrn Hofrat Prof. Schottelius für die Erlaubnis, in seinem Institut arbeiten zu dürfen, meinen besten Dank abzustatten. Den Herren Dr. Erne und Dr. Lehmann sei für ihre freundliche Hilfe bestens gedankt. 